\title{
SHELTERBELTS FOR THE PRAIRIES
}

\section{By D. I. Crossley}

W

ESTERN CANADA, that is, southeastern Alberta, southern Saskatchewan and southwestern Manitoba, has been suffering from drought for the last five or six years. The precipitation has been subnormal with the result that the water table has lowered, lakes, sloughs and streams are drying up and the soil is drifting. Farmers throughout this region have suffered total crop failure during these years and in the majority of cases have either gone on relief or have abandoned all that they have built up and taken homesteads on the available land north of the North Saskatchewan River.

The same drought conditions have been effecting the United States throughout their plains and they are planning a tremendous project in an attempt to alleviate them. They propose "to plant shelterbelts on the plains to an extent and degree sufficient to have some measurable effect on the physical conditions of the area. ${ }^{\text {th }}$ According to the plans "the extent and degree" constitutes the planting of one hundred parallel windbreaks approximately one hundred and twenty feet wide, each one mile apart and over one thousand miles long, which covers an area of approximately one hundred thousand square miles from the Canadian border of North Dakota to the Panhandle of Texas. The planted strips within the belt will constitute one and one-half million acres.

It seems that this tremendous scheme was launched upon the suggestion of the President of the United States with the idea of ameliorating the climate throughout the Central States so that the farmers resident there would be able, in the future, to raise good crops and maintain the standard of living to which they had grown accustomed. However, before launching this program, those responsible appear to have erred in not obtaining technical advice from Foresters and other scientists in the position to give a studied opinion.

Upon the announcement of this gigantic undertaking, the press, throughout the length and breadth of the land, pounced upon it as good copy and articles and editorials were published both for and against, in countless numbers. It is safe to say that public opinion has never before been raised to such an extent over a subject so closely related to Forestry with the possible exception of the C.C.C. As was to be expected, Foresters every. where were asked to give their opinions as to the feasibility of the undertaking and because the idea was sprung upon them with no warning, they of course had no considered or united answer. The public soon noticed this lack of 
harmony in the answers, and commenced ridiculing the Foresters' professional standards. To the man on the street Forestry consists of tree planting and so it is only natural that he should be surprised at the diversity of opinions set forth. The profession of Forestry, as you all know, is waging a difficult battle to have its men classed on a plane with the accepted professions of Medicine and Law, and it is to be regretted that sufficient warning was not forthcoming to enable the formation of a united policy.

The farmers on our prairies are reading about the American Shelterbelt project and already they are clamouring for something similar. The governments realize that something must be done soon to prevent the effected area from becoming a desert, and the Saskatchewan government has appointed a Commission of Conservation and Afforestation to collect data on the matter. Local, agronomists are devoting much time to the question, as are the numerous farmers' papers throughout the country. The feasibility of planting trees is one of the main themes in the discussions and you may at any time be called upon for advice, and it would be wise to benefit from our colleagues' mistake across the border and be ready with a considered answer.

My interest in this question lies in the fact that my home is in the west. I have been through these drought areas a good many times and realize the need for action, and I have collected considerable data on the pros and cons of the shelterbelt idea with the hope that you may find them useful in forming your conclusions.

The topics that I wish to discuss are as follows-

1. Why are the prairies treeless?

2. Will trees grow on the prairies?

3. In what way will trees influence the climate?

4. What influence will shelterbelts have?

1. WHY ARE THE PRAIRIES TREELESS?

The prairie provinces may be divided roughly into three zones. The northernmost is composed of lakes, forest and muskeg and its southern border may be considered as the north branch of the Saskatchewan River. The middle zone is what is known as the park or bluff belt. It has clumps of trees, chiefly poplar, scattered over its area and is a rolling country. This zone probably averages between fifty and one hundred miles in width and gradually merges into the third zone which is the true prairie where the terrain is flat and the monotony is not broken by scattered bluffs, although trees do exist here and there in coulees and around bodies of water.

The fact that the prairies are treeless has long excited the curiosity of man. If the riddle could be solved it would supply the answer as to the feasibility 
of covering the prairies with arboreal growth. Many theories have been brought forward from time to time to answer the question but none of them appears to stand up to a stiff cross-examination. It seems probable however that the truth lies in an admixture of parts of some of these theories and not altogether in one.

Dr. Fernow ${ }^{1}$ believed that the whole earth's surface could be considered as potential forest land. If there is sufficient moisture and not too great heat or cold, tree growth, because of its perennial nature and its power to shade cut the lower forms of vegetation, will ultimately prevail even though it takes geological ages. He attributes the fact that trees have not invaded the prairies to the former presence of buffalo and to continual fires. It is difficult to imagine that even the countless hordes of buffalo that did range seasonally over this country could have any appreciable soil-compacting effect over this huge area, which of course must include the plains and prairies of the United States. The grass must have been plentiful also, and it is doubtful whether the animals would brouse on tree seedlings with much more succulent fodder available. His theory of fire, however, is much more plausible, and has been advanced by many as the cause in itself.

After the retreat of the last ice sheet, vegetation invaded the area and when the grass stage of the succession was reached it stopped because of fires. The fertile soil produced luxuriant grass which became like tinder during the dry period in late summer. Any fire started would sweep before the wind over a great area. If these fires occurred frequently, the establishment of tree seedlings would be prevented, while the growth of grass would be stimulated. Only recently, say in the last forty or fifty years, has the occurrence of these periodic fires been checked and that is not sufficient time to permit a noticeable invasion of trees from the neighboring forests. In most places now that fires are prevented the cultivation of the soil for agricultural purposes provides an equal hindrance to tree establishment.

Other supporters of the fire theory think that the area was at one time partially covered with forests. During extensive dry periods the grass became dry and combustible and when a fire started, either naturally or with the aid of Indians who wished to provide fresh grass for the buffalo and for their ponies, it would sweep into the neighboring forests. A new crop of grass and weeds would, of course, follow, to be followed by other fires, and so on. The establishment of tree seedlings would be prevented and a thick grass sod would be built up which would not favor them. This theory is supported by the fact that on the eastern edge of the prairies long tongues of forest jut out such as would be left by advancing forest fires. It may be 
argued that fires would leave traces of charcoal which of course is very imperishable. However, it is claimed that continual fires burning year after year, as the prairie fires no doubt did, would reduce the remaining debris to ashes.

Another theory that may contain much truth is one attributing the cause to lack of drainage. The flat prairies provide little surface run-off and an almost impervious hardpan prevents any appreciable underground drainage. The greater proportion of the rain that falls is evaporated back into the air again with the consequent deposition of the soil salts which may become concentrated enough to prevent the growth of the higher plants. The presence of so many alkali deposits throughout the West is sufficient proof of the accumulation of these soil salts. In a great many cases these alkali sloughs are ringed around with a belt of trees which seems to point to the fact that, because of the run off into the basin, the soil salts have not accumulated on the slopes in harmful quantities or combinations and trees have consequently established themselves there. The weakness of this theory lies in the fact that trees can be grown on the prairies with no care being taken to remove this supposed accumulation of salts.

I have mentioned the fact that trees grow naturally in the park belt and yet they are absent on the prairies. It seems quite possible that if we could find what the difference is between the two areas we would have the answer to the riddle. There is little or no difference in the soils, and precipitation figures taken over a period of thirty years show a surprising thing. The yearly precipitation in the southern section of Saskatchewan (in which we will include the area below Saskatoon) averaged 16.62 inches, and the seasonal precipitation, by which we mean that received from April to July, averaged 8.11 inches. The yearly precipitation in the northern section averaged 13.90 inches or 2.72 inches less than in the south, and the seasonal precipitation was 6.98 inches or 1.13 inches less. Now it can be seen that less moisture falls in the northern section and yet trees grow there naturally. The only explanation seems to be that more of this moisture must be conserved in the park belt than in the south, where the rate of evaporation is very high. It would seem feasible to suppose then, if this high evaporating rate could be reduced in the south, trees could be grown there with little difficulty, and, if given the chance, might even spread naturally.

\section{WILL TREES GROW ON THE PRAIRIES?}

H. H. Chapman, President of the Society of American Foresters, edited in the Journal of Forestry ${ }^{2}$ a symposium gleaned from the opinions of men who have had direct experience with the growing of trees on the plains. The 
variety of opinions expressed is, to say the least, disturbing. Some of the correspondents claim that trees can be successfully grown on these areas even in the worst drought years, as long as they are given the requisite care and attention, and they quote areas of established belts to prove their contentions. On the other hand others are just as emphatic in their claims that trees can not be successfully grown there, despite all possible care, and they also submit evidence to support their claims. Professor Chapman must have had a difficult task to come to a conclusion from that mass of conflicting data. He says "this is a region where trees do not grow naturally except under 'hothouse' conditions, that is, where local conditions supply water in excess of the natural rainfall. Hence the region is submarginal for forest plantations as such, and any trees produced there will require initial thorough soil preparation, continuous cultivation for several years, and fencing for protection not only from cattle but from rabbits. On heavy clay soils, or on alkaline areas no success can be expected even with the utmost care. Where the soil permits of tree growth the rate of height growth is slow and the trees are relatively shortlived. Unusual droughts like those of 1934 cause the death of most of these plantations."

However, due probably to slightly different conditions we need not be worried over the possibility of trees not growing on our prairies as long as we observe established methods. We may agree that these lands would never produce a forest naturally, but too many attempts to establish belts have met with success for us to agree that it is a "hothouse" scheme. Norman Ross, Chief of Tree Planting at the Indian Head Experiment Station in Saskatchewan, has had over thirty years' experience in this field all over the three prairie provinces, and I will quote him from private correspondence. He says "our experience in dealing with prairie plantings in Manitoba, Saskatchewan and Alberta would indicate that where soil is not alkaline or drift sand, trees can be grown and successfully maintained if proper methods are followed out and suitable varieties used. Providing (and this seems important) that precipitation is normal for the first two or three years after planting. During a period of dry years the establishment of plantings is extremely hazardous."

"We find that Caragana, Green Ash, American Elm, Scotch Pine and White Spruce, when once established, can withstand a very great deal of drought. Considerable areas in southwestern Manitoba and southern Saskatchewan have for the past three to five years suffered from extreme drought conditions. It is surprising to find the shelterbelts in these areas, in many cases badly neglected, standing up so well. As a result of observations in these areas I am fairly well satisfied that it is quite practical to grow trees 
anywhere under prairie conditions where soil conditions are at all favorable, once they become established. Success depends on:-

1. Proper preparation of soil carrying a reserve of moisture. (We insist on summerfallow).

2. Suitability of stock selected for planting.

3. Cultivation until trees have grown close enough to crowd out weed growth and maintain a ground cover.

4. Protection from stock and fire."

Many writers, discussing the feasibility of planting shelterbelts, claim that they could not survive where the soil drifting is bad because they would soon fill up with blown sand and the trees would die. Ross says "soil drifted in during extremely high temperatures is much more injurious than drifting occuring in cool weather. I have seen belts drifted to a depth of 3 and 4 feet which do not seem to suffer very seriously." However, to establish the belts some method for fixing the soil must precede planting.

The different species of trees vary in the degree to which they are injured by rabbits, with the Caragana, which is the hardiest and probably the most desirable tree to grow, being practically immune from attack and having the additional advantage that it is not necessary to protect it from stock by fencing.

In general then, it is safe to say that wherever cereal crops can be grown successfully trees can also be grown if given the requisite care. This care does not include artificial watering as many of our American colleagues contend, but does include proper cultivation of the soil so as to reduce the evaporation rate to the minimum.

\section{IN WHAT WAY WILL TREES INFLUENCE THE CLIMATE?}

Practically all of us, without giving it any thought, imagine that almost all of our precipitation comes from water evaporated directly from the oceans. However, engineers, in computing the discharge of rivers, find that only a very small percentage of the rainfall over the drainage area is returned to the sea by the river. The large area drained by the Saskatchewan River at The Pas has a mean annual precipitation of about fifteen inches. Of this amount approximately three and one-half inches annually is returned to the ocean through the Nelson River. Deep seepage on this area is so small that it may be ignored; hence eleven and one-half inches must be forced into the atmosphere by evaporation and transpiration. ${ }^{3}$ Here it is available for recondensation. To quote Dr. Zon - "if precipitation over land depended only upon the amount of water brought directly by the prevailing winds from the ocean, the land would be pretty arid and the rainfall would be confined to a 
narrow belt close to the ocean. Fortunately not all the water that is pre* cipitated is lost from the air currents, a part runs off into the rivers or percolates into the ground, but a large part of it is again evaporated into the atmosphere. The moisture-laden currents therefore, upon entering the land, at first lose their moisture which they obtained directly from the ocean, but in their farther movement into the interior they absorb the evaporation from the land. At a certain distance from the ocean practically all of the moisture from the air must consist of the moisture obtained by evaporation from the land. At least it must form a larger part than the water which was obtained directly by evaporation from the ocean.

"The vapor brought by the prevailing winds from the ocean is many times turned over and reinvested before it is returned again to the ocean through the rivers.

"If we could reduce the surface run-off, and at its expense increase the evaporation from the land, we should thereby increase the moisture of the passing air currents, and in this way contribute to the precipitation of that region into which the prevailing winds blow. This conclusion is almost axiomatic and there can be no dispute about it."

It is well known what tremendous amounts of water trees give off to the atmosphere; that a forest transpires more water than a similar area under any other type of vegetation, or that is evaporated from the bare soil or even from a corresponding water surface. Thus if Dr. Zon's contentions are admitted it will be seen that it is desirable to have the prevailing winds blowing over a forested area rather than over any other surface.

However, while we may be prepared to admit the truth of these statements, it will be seen that where forests have an influence on the precipitation in the surrounding regions, shelterbelts, because of their scattered nature will not have anywhere near the same affect, and it is very likely that their influence would be negligible. Thus I do not contend that the planting of shelterbelts will increase the rainfall throughout a region. However, great forested areas lie to the north and west of the prairies and it is conceivable that they have a relaying affect upon the moisture, and these regions must he maintained and even increased with forest cover.

I have heard prominent meteorologists say "that even if trees do put moisture into the atmosphere how are we going to get it out again?" There may be plenty of moisture in the air and yet if it is not precipitated little benefit can be obtained from it. A case in point would be the southern end of California. On the west coast lies the Pacific, and the westerly winds bring moisture laden air over the land. You would expect a region of luxu- 
riant growth and instead there is a desert. And why?-because although the moisture is present there is no means of causing it to condense and so precipitate. However, I fail to see how this concerns us as we have a method for condensing the water out of the atmosphere. Warm winds coming from the south meet cool winds from the north. The southern winds contain the greater part of the moisture and when they meet the cool north winds they are forced up and cooled and condensation results. Therefore the more moisture that we can put into the air at the expense of run-off and percolation the more will be available for condensation.

The high rate of evaporation is undoubtedly the greatest factor in the dissipation of moisture on the prairies. The winds leave the Pacific Ocean laden with moisture but in their passage over the coast range and later over the Rocky Mountains they are drained of most of this and by compression have become much warmer. Thus instead of bringing much needed moisture to the prairies they are hungry for it themselves. The dreaded chinook winds in the spring of the year have been known to entirely demolish two and one-half feet of snow in twelve hours. Here shelterbelts will have an appreciable affect, for, by lessening the velocity of the wind they will cut down the rate of evaporation and transpiration.

\section{WHAT INFLUENCE WILL SHELTERBELTS HAVE?}

When the land in the west was first broken it was prevented by the heavy mass of fibre from drifting, but after years and years of cultivation with no attempt to replenish it, this fibre has disappeared and the fine soil particles, with nothing left to bind them together, are easily picked up and transported by the winds. The widespread system of summerfallowing has served to aggravate this condition. Summerfallowing has been necessary to store up moisture in the soil and to eradicate weed growth but it has left the ground bare for the winds to play havoc with. The condition has become so bad that in the last few years of drought the farmers have had difficulty in keeping the seed in the ground long enough for it to germinate. Many farmers, after one drilling of seed has blown out, seed again and again, until it is too late in the season to try once more. Even if they are successful in getting a catch, the soil may drift so badly as to leave the roots of the seedlings bare and they die from exposure. It will be seen then that the prevention of soil drifting is a major problem in reclaiming these areas.

There are two methods of overcoming this condition. The first is to bring the soil back to its former fibrous state, and the second is to lessen the velocity of the winds so that their transporting powers will be nil. The first method is in the hands of agronomists and need not concern us here, but the 
second may be brought about by shelterbelts and thus we are directly interested.

The question that we must concern ourselves with is to what extent will the planting of belts of trees prevent the drifting of the soil. It must be remembered when we talk of reducing the velocity of the wind that the moving air is seven or eight miles deep and anything that we may do on the surface of the globe will be Lilliputian as far as affecting the whole mass is concerned. However much we may despair in our inability to effect this power we can console ourselves with the fact that we are not interested in what the air does very far above the surface of the ground, as long as we can modify its affect at that surface.

When the wind is blowing over hilly country the horizontal current impinging against the side of the hill is, by its inertia, driven upwards. It descends again to strike another hillside and the same action takes place. The result is an undulating or hopping motion. Loss in horizontal velocity thus occurs, due to the interference of these uprising and downflowing currents with the ground and with each other.

Snowdrifts provide a practical and visible demonstration of the protection that any obstruction provides against wind on its leeward side and for that matter a short distance on its windward side. It seems to be generally accepted that the leeward side is protected one rod for every foot in height of the obstruction. However, this distance must naturally depend on the location of the field, type of soil, area to be protected, tightness of the wind. break and so on. A point to be remembered is that the greater the velocity of the wind the greater the area that will be protected.

Some writers claim that the influence of successive shelterbelts will be cumulative, that the velocity of the wind will be lessened as more and more belts are passed. There is little or no evidence to support this contention, and it seems unreasonable to suppose its truth when we remember that the air current is of so great a depth. The friction of the tree tops may retard the motion somewhat, but it is quite to be expected that the air currents above will overcome this affect very shortly with their pull on the lower layers.

The protection of one rod for every foot in height is not a great distance and it would take an enormous number of belts to completely stop this soil movement. However, the soil movement must be stopped, and if this is the only way, then the magnitude of the task must be disregarded. The belts have other benefits that help to compensate for the trouble of establishing them. They have a marked effect on surface evaporation. To quote Bates 
from "Windbreaks, Their Influence and Value," "the efficiency of a windbreak in checking evaporation is proportional to its density. It may save at a single point in extreme cases seventy per cent. of the moisture usually lost by evaporation... The protection is appreciable for a distance equal to five times the height in the windward direction and fifteen to twenty times the height to leeward." In a table on page fifty in the same publication Bates shows that increasing the velocity of the wind results in decreased evaporation. The belt was an underplanted cottonwood grove and measurements were made to ascertain the percentage of moisture saved in an area twelve times as wide as the height of the trees at different wind velocities. With wind blowing at 5 miles an hour the moisture saved was $23.3 \%$, at 10 miles per hour $31.9 \%$, at 15 miles an hour $38.7 \%$ and at 20 miles an hour $40.1 \%$.

This decrease in evaporation will result in a greater crop yield. T. C. Main in his paper "Drought and Soil Drifting in Western Canada" mentions a field which was protected with a hedge. He states that the yield on a five hundred foot strip adjacent to the hedge was just double that on the next five hundred foot strip. Thus if the yield was doubled by using hedges then the increased yield would more than pay for the initial cost of planting the hedge in the first year. If we suppose a hedge ran one-half mile and it doubled the crop on the area five hundred feet to the leeward, a very conservative figure would be an increase of ten bushels per acre. The area would include thirty acres and thus a profit of three hundred bushels would be reaped. Sold at seventy cents a bushel it would bring two hundred and ten dollars, and two hundred dollars would more than cover the cost of estab. lishing five or six rows of trees for one-half mile.

The belts would serve still another purpose by acting as a trap for winter snow fall. On the bald prairies the high winds carry practically all of the snow off the land and deposit it in draws and coulees. The average yearly rainfall is approximately fifteen inches, of which four inches comes in the form of snow. It is safe to estimate that at least two inches of this snow is carried to the coulees, the rest being either evaporated or left on the land. In the spring when the snow melts, all that has collected in the coulees will be carried away to sloughs, lakes and rivers and the farm land will receive little or no benefit from it. If, however, this snow was kept on the land by drifting around shelterbelts, it would melt slowly in the spring and seep into the ground and almost two extra inches of moisture would be available for plant growth. It might be argued that these drifts around the belts would be slow in melting in the spring, and would keep the farmer off the land 
when he should be seeding. However, for the additional moisture gained, I believe that the farmer would be willing to delay his seeding a few days.

The belt may also injuriously affect crops by sapping moisture from the adiacent land. This area may vary from one to five times the height of the trees according to the species and the situation. This can be minimized by cultivating the land deeply and by selecting species of trees for planting that are tap-rooted.

The fact that the belts shade the soil may have an affect on the seed production of the crop, as it seems that they require more light for seed production than they do for vegetative growth. The effect of course will be greatest in the case of north-south windbreaks. If the damage is found to be serious the shaded area can be used for growing forage crops.

The affect of the windbreak upon the temperature of the air in the zone of its influence is appreciable. The daily range in temperature is nearly nine degrees $F$. greater in the protected area than where the air is allowed to circulate freely. ${ }^{5}$ The windbreak thus produces "hothouse" conditions and since it also reduces evaporation the combination is beneficial. This benefit is particularly appreciated in the spring, when all the heat procurable is needed for germination.

I do not believe that it is our place to recommend any specific methods of alleviating these drought conditions. Many other methods, besides tree planting, have been suggested, and some of them may contain great possibilities; methods such as strip farming, irrigation, planting of the area to grass to bring back the old sod condition, damming up streams and creeks to provide greater surfaces of water to evaporation, even down to the laissez-faire, or as one has so aptly expressed it, the lazy fairy attitude, that nothing be done but wait for the return of the wet cycle again, in the meantime sub. sidizing the farmer with the hope that he would pay it back when he did get a crop. However much truth there may be in any of these methods they need not concern us here as we are only interested in our side of the question and can leave the task of working out a remedy to those who are in the field and are thus better supplied with information. If we can support our phase of the question in a convincing manner then we will have done all that is expected of us.

\section{SUMMARY}

1. The exact reason why trees do not grow naturally on the prairies is not known, but it is here attributed to the high rate of evaporation, together with the accumulation of soil salts toxic to trees with possibly the theory of fire thrown in as a removal factor. 
2. Trees will grow on the prairies if given the requisite care and attention.

3. Large areas of forest will serve as relayers of moisture to a greater extent than will a similar area under any other type of vegetation, a bare area or a corresponding water surface. This however, cannot be claimed of windbreaks because, even if massed all together they would not amount to an extensive body of trees such as is necessary for this effect.

4. Shelterbelts will decrease the movement of the wind resulting in decreased evaporation, increased moisture conservation in the form of snow, and decreased soil movement. They will produce hothouse conditions during sunlight, but they will be disadvantageous in that they will sap the moisture from the immediate soil and they will shade the soil.

\section{REFERENCES}

1. Fernow, B. E. 1891. Report of the Chief of the Division of Forestry for 1891.

2. Chapman, H. H. 1934. The Shelterbelt Project. Journal of Forestry, Vol. 33 , No. 9.

3. Main, T. C. 1931. Drought and Soil Drifting in Western Canada.

4. Zon, R. The relation of Forests in the Atlantic Plain to the Humidity of the Central States and Prairie Region.

5. Bates, C. G. 1911. Windbreaks: their Influence and Value. U. S. D. A. Bulletin 86.

Other references used-

(a) Pros and Cons of the Shelterbelt, American Forests, Nov. 1934

(b) Butler, Ovid. The Prairie Shelter Belt. American Forests, Sept. 1934.

(c) Conservation of Soil Fertility and Soil Fibre. Report of the Commission of Conservation, Canada, 1920.

(d) Huntington, E. Marginal Land and the Shelter Belt. Journal of Forestry, Vol. 32 , No. 8.

(e) Gaskill, A. Why Prairies are Treeless. Proceedings of The Society of American Foresters, 1906, Vol. 1. No. 3.

(f) Campbell, R. H. Why the Prairies are Treeless. The illustrated Canadian Forestry Magazine, 1921. Vol. 17, No. 1.

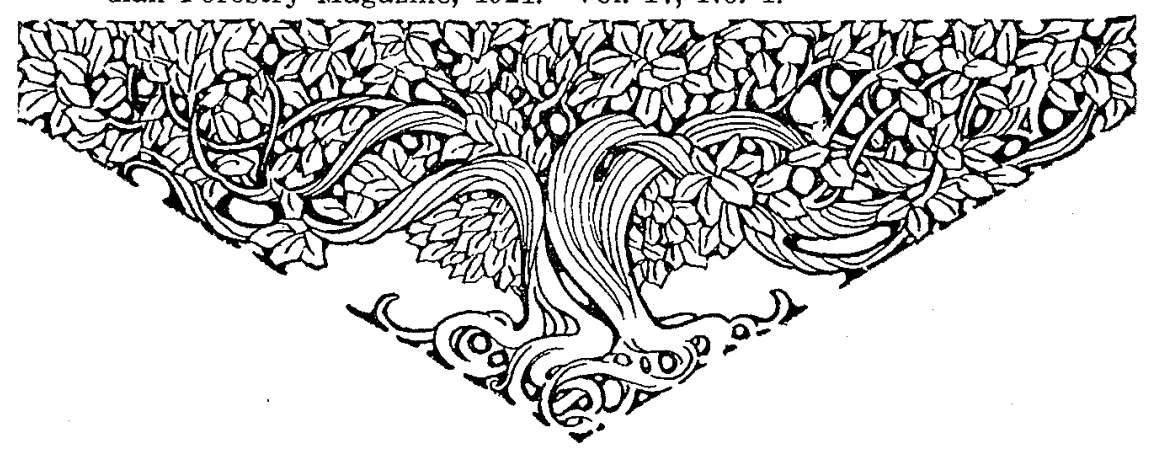

